\title{
POSICIONES POLÍTICAS VS MERCADO ELECTORAL
}

\author{
Octaviano Moya Delgado
}

\begin{abstract}
Resumen
El presente trabajo muestra una revisión del voto dividido que ha generado un proceso de alta competitividad en Mazatlán, Sinaloa. Se confronta a las posiciones políticas de los electores con las opciones de competencia electoral. Para ello se parte de la hipótesis que el comportamiento electoral se produce más a consecuencia del análisis individual de los electores sobre beneficios (utilidad) que ofrecen candidatos y partidos que compiten en las elecciones que por las características de tipo político-ideológico de los propios electores. Para comprobarlo se analizan tres dimensiones empíricas, en las que están: el contexto y los actores en la elección, las condiciones de competencia, posiciones político-ideológicas y utilidad del voto.
\end{abstract}

Palabras clave: Voto Dividido; Alta Competencia Electoral; Utilidad del Voto; Posiciones Político-Ideológicas.

\begin{abstract}
This work shows a revision of the divided vote that has generated a process of high competitiveness in Mazatlán, Sinaloa. It confronts the political positions of the voters with the options of electoral competition. To do this on the assumption that the electoral behavior occurs more as a result of the individual analysis of the voters on benefits (utility) that offer candidates and parties competing in the elections, which the characteristics of political-ideological of the voters themselves. To check it, it is analyzed three empirical dimensions, in which are: the context and actors in the election, the conditions of competition, positions politico-ideological and utility of the vote.
\end{abstract}

Keywords: Divided Vote; High Electoral Competition; Utility of the Vote; Positions Politico-Ideological.

\section{Introducción}

El cambio en la intención del voto durante las campañas es uno de los fenómenos políticos más vistos actualmente. Para analizar dicho fenómeno, se buscó confrontar los cambios originados en la competencia electoral con las posiciones políticas de electores que se desprendían del conflicto entre las fuerzas políticas nacionales, en un municipio que mostraba alta competitividad electoral, como lo es Mazatlán, Sinaloa. La hipótesis planteada era que el comportamiento electoral se produce más como consecuencia de los beneficios (utilidad) que ofrecen candidatos que compiten, que sobre las posiciones políticas de los propios electores. Para comprobarlo se adoptaron como dimensiones empíricas el contexto y los actores en la elección, posiciones político-ideológicas, los beneficios esperados (utilidad), las condiciones de competencia. El primero consideró a electores, candidatos y 
partidos; las posiciones políticas de tipo ideológicas (izquierda-derecha), políticas (Andrés Manuel López Orador - AMLO/Vicente Fox Quezada - VFQ); programáticas (Adultos Mayores-Oportunidades, instalación de casinos, responsabilidad del gobierno). En la utilidad del voto, se consideró indagar las evaluaciones retrospectivas con la situación económica y el desempeño de los gobiernos estatal/municipal, evaluaciones prospectivas, mediante la comparación entre los candidatos hacia un mejor gobierno y el orden de preferencias. En las condiciones de competencia, se analizaron las tendencias electorales, el momento en la decisión del voto y los resultados electorales como elementos que muestran los cambios en el voto. La exposición se aborda en dicho orden y al final se retoman aspectos relevantes a manera de conclusiones.

\section{El Contexto político y los actores en la elección: La elección en 2004}

A partir del año 2000 en México, el gobierno de VFQ surgido de la alternancia tuvo grandes problemas para realizar los cambios que había propuesto durante la campaña. La incapacidad para generar acuerdos con otras fuerzas políticas, desaciertos en la política exterior, altos niveles de inseguridad provocado por el narcotráfico, escaso crecimiento y desempleo, crearon el desencanto entre los electores que los habían apoyado. Por el contrario, la alta popularidad de AMLO como Jefe de Gobierno del Distrito Federal (JGDF), puso en estado de alerta al grupo en el poder previo a las futuras elecciones presidenciales de 2006.

De tal forma que desde el 2003 dos elementos iniciaron un conflicto entre las fuerzas políticas: la elección de los consejeros del Instituto Federal Electoral (IFE) y el proceso de desafuero en 2004 que llevó al país a una fuerte confrontación política y social. La renovación de los Consejeros del IFE se observó como una componenda entre partidos de derecha (PAN/PRI/PVEM), con la exclusión de los izquierdistas (PRD/PT/Convergencia). Los nuevos integrantes del órgano electoral fueron designados sin consenso, en una acción vista como ofensiva para tener al árbitro de su lado. El desafuero contra AMLO tuvo como fundamento el desacato a una resolución de un juez de distrito. Enfrentar el proceso jurídico lo llevaría a perder sus derechos políticos e impedir que compitiera en la elección presidencial de 2006. El litigio desbordó los límites jurídicos y rápidamente se convirtió en una confrontación política ampliamente debatida en los medios de comunicación. La trascendencia del hecho fue captada por los medios de todo el país, además el PRD, partido al cual pertenecía AMLO organizó una serie de eventos ciudadanos cuyo objetivo fue demostrar el rechazo de la sociedad hacia el desafuero. En este marco se realizaron 14 elecciones en las entidades del país.

Una de ellas fue Sinaloa, una entidad enmarcada en el noroeste de México. En ella el comportamiento electoral ha sido cambiante durante las últimas tres décadas. Aplicando el Índice de Pederson se observa que los municipios que presentan mayores niveles de competitividad son Ahome, 
Culiacán y Mazatlán. Éste último ha mostrado desde los ochenta una fuerte competencia entre el PRI-PAN, con un comportamiento electoral fluctuante en los últimos procesos electorales. El resultado en las elecciones entre el candidato triunfador y su más cercano contrincante ha sido menor a 3 puntos porcentuales de la votación. Pero ese sistema bipartidista de se ha ampliado también hacia otros partidos generando algunas alternancias. Como es el caso del PT en 2001, donde logró el triunfo creciendo en más de 30 puntos porcentuales (Cuadro 1).

Cuadro 1 - Competitividad electoral en los municipios de Sinaloa en elección de Ayuntamiento

\begin{tabular}{|c|c|c|c|c|c|c|c|c|c|}
\hline \multirow{2}{*}{ Elección } & \multicolumn{2}{|c|}{ Culiacán } & \multirow{2}{*}{$\begin{array}{l}\text { Índice } \\
\text { Pederson }\end{array}$} & \multicolumn{2}{|c|}{ Mazatlán } & \multirow{2}{*}{$\begin{array}{l}\text { Índice } \\
\text { Pederson }\end{array}$} & \multicolumn{2}{|c|}{ Ahome } & \multirow{2}{*}{$\begin{array}{c}\text { Índice } \\
\text { Pederson }\end{array}$} \\
\hline & PAN & PRI & & PAN & PRI & & PAN & PRI & \\
\hline 1983 & 39 & 53 & .92 & 43 & 49 & .93 & -- & -- & --- \\
\hline 1986 & 38 & 57 & .95 & 47 & 50 & .97 & 41 & 57 & .98 \\
\hline 1989 & 40 & 49 & .89 & 46 & 44 & .90 & 41 & 49 & .90 \\
\hline 1992 & 46 & 50 & .96 & 49 & 49 & .98 & 15 & 82 & .97 \\
\hline 1995 & 49 & 40 & .89 & 46 & 44 & .90 & 49 & 41 & .90 \\
\hline 1998 & 39 & 45 & .84 & 37 & 34 & .71 & 41 & 45 & .96 \\
\hline 2001 & 33 & 47 & .80 & 29 & $28 / 40$ & .97 & 37 & 60 & .97 \\
\hline 2004 & 44 & 49 & .89 & 48 & 45 & .93 & 24 & 67 & .91 \\
\hline 2007 & 22 & 69 & .91 & 40 & 49 & .89 & 31 & 51 & .82 \\
\hline
\end{tabular}

Fuente: Elaboración propia con datos obtenidos del CEE.

En la elección de 2004 compitieron por la gubernatura: Heriberto Félix Guerra (Félix-PAN); Jesús Aguilar Padilla (Aguilar-PRI); y Audómar Ahumada Quintero (Audómar-PRD). Para el Ayuntamiento de Mazatlán: Alejandro Higuera Osuna (Higuera-PAN); Miguel Ángel García Granados (Granados) por la alianza Mazatlán nos Une (PRI/PVEM/PBS); y Dino Durán Ibarra (Durán) Candidato Común (C/PT/PRD). Para diputados locales en el distrito XIX compitieron: Carlos Eduardo Felton González (Felton-PAN), Irma Leticia Tirado Sandoval (Tirado) de la alianza Mazatlán Nos Une (PRI/PBS); Julio Cesar Rodríguez Pasos (Pasos-PRD). En el distrito XX compitieron: Nadia Haydee Vega Olivas (Vega-PAN); Gonzalo Figueroa Carrillo (Figueroa) de Alianza Mazatlán Nos Une (PRI, PVEM, PBS); Moisés Carrillo Sánchez (CarrilloPRD); José Roberto Osuna Amezquita (Osuna-PT).

En lo que respecta a los electores, entre simpatizantes e independientes pueden destacar características sociodemógráfica y políticas. En las primeras, se observó que los simpatizantes no constituyen grupos homogéneos ya que se diferencian por ingreso, escolaridad, zona de residencia. Las políticas, que toman en consideración la intensidad y dirección en la simpatía partidaria, se encontró que $77 \%$ dijo no sentir lazo afectivo, mientras que $23 \%$ expresó simpatizar con alguno de ellos. Éstos últimos, un $43 \%$ simpatizó con el PAN, $44 \%$ al PRI, $13 \%$ con PRD. En cuanto a la intensidad, $42 \%$ pronunció alto grado de simpatía, $48 \%$ medio y $10 \%$ bajo. Entre los priístas y panistas fueron cercanos a $17 \%$ alto grado, $21 \%$ medio, y $4 \%$ bajo y entre perredistas $8 \%$ dijo tener alta simpatía, $4 \%$ media y $2 \%$ 
baja. Sin embargo, la influencia sobre la decisión del voto solo se observó entre panistas con alto nivel de simpatía ya que con priístas y perredistas en la medida en que el nivel de simpatía disminuía la relación con el voto se debilitaba. En tal sentido, fue necesario conocer las posiciones políticoideológicas y la utilidad que significaba el voto hacia ellos para definir la orientación de su voto.

\section{Posiciones políticas-ideológicas}

Desde la década de 1950 los estudios de Berelson, Lazarfeld, y McPhee (1954) sostenían que las etiquetas ideológicas eran de enorme ayuda de simplificación en la decisión electoral (MORENO, 2003). Pocos años después Anthony Downs con su Teoría Económica de la Democracia (1957) fortaleció dicha afirmación, pero fue más allá al crear un modelo espacial de competencia, en donde planteaba que los electores asumían preferencias individuales - completas, fijas y transitivas - representadas en el espacio político $N$-dimensional. De esta forma:

i. Cada votante tiene un conjunto ideal de posiciones políticas que estará representado por un punto en un espacio hipotético $\mathrm{N}$-dimensional.

ii. Un candidato o una opción política tendrá una determinada posición que estará representada en un punto en el mismo espacio.

iii. $\quad$ El votante elige al candidato cuya posición este más próxima a la suya.

Este modelo espacial dio lugar a diversas conceptualizaciones del voto. Una de ellas es el voto racional, que predice que el elector otorga su voto al candidato del cual espera mejor desempeño en relación con los aspectos más relevantes para su vida. Bajo este esquema se distinguen dos líneas que guían la decisión electoral. La primera, considera cambios en el bienestar económico en un periodo previo, con lo que podría preguntarse: ¿qué ha hecho por mí el partido en el gobierno?, realizando evaluaciones retrospectivas sobre el estado que guarda la economía nacional, personal o familiar. En la segunda, el votante se cuestiona sobre la posibilidad de que llegara determinado candidato al gobierno, ¿qué hará por mí? Para dar respuesta realizaría una evaluación prospectiva utilizando la información obtenida a través de los medios o candidatos para determinar sus posiciones y calcular futuros beneficios. Con estas consideraciones, se analizaron las posiciones político-ideológicas y su relación con el voto (FIORINA, 1981, p. 324-327).

La primera de ellas compete a la ideología. Para la lógica de Downs las ideologías eran útiles tanto a partidos como a votantes. Los partidos advertían que algunos ciudadanos elegían de acuerdo con las ideologías y no con las políticas, proponiendo en consecuencia ideologías atractivas para los 
electores ${ }^{1}$. En México se ha observado una fuerte relación entre orientaciones individuales y preferencias partidistas. Aunque éstas definen las dimensiones de la competencia política con base en líneas más relevantes de conflictos presentes en la sociedad. Con ello, la izquierda y derecha se encuentran en la política mexicana en una multiplicidad de referentes históricos, económicos, políticos, sociales, culturales y de sentido común. A pesar de tanta diversidad y definición ideológica en los partidos políticos, los mexicanos han sido capaces de atribuirles un significado y tomar posturas en un continuo político entre ambas (MORENO y ZECHMEISTER, 2003) ${ }^{2}$. Por otro lado, estudios realizados en Sinaloa han abordado la relación que guarda la posición ideológica de los electores con su voto (MOYA, 2003).

Por este motivo, se preguntó a los electores, mediante una técnica de autoubicación, su posición ideológica para posteriormente verificar la relación que existía con su voto. Sobre ello se observó un desplazamiento desde la izquierda hacia el centro y centro-derecha. Los cambios más evidentes se dieron entre los que se encontraban a la izquierda, ya que los ubicados tanto en la izquierda y centro-izquierda disminuyeron de $34-23 \%$, de centro de 21 $28 \%$, y centro-derecha de $16-22 \%$ de agosto a octubre. Con los simpatizantes únicamente se observó una disminución entre los de centroizquierda y un incremento en los de centro-derecha. Pero de manera particular, un tercio de los panistas en agosto se encontraban en centroderecha, $(24 \%)$ la izquierda y (19\%) centro, pero conforme avanzó la campaña se desplazaron hacia la derecha (43\%) en septiembre, para posteriormente en octubre ubicarse desde el centro hacia la derecha. Los priístas, en agosto, la mitad se ubicaban en la derecha y más de un tercio en el centro, para septiembre se observó un desplazamiento hacia los extremos y para octubre quedaron estacionados en la derecha y el centro con una presencia importante en la izquierda. Entre los perredistas un tercio se ubicó en agosto en el centro izquierda, con igual presencia (17\%) en los demás puntos de la escala. Para septiembre se observó un desplazamiento hacia la derecha $(40 \%)$ y en centro-derecha $(20 \%)$, centro e izquierda. Para octubre nuevamente se movieron hacia la derecha (37\%) en el centro-derecha y la derecha (Cuadro 2). La enorme movilidad respecto a la ubicación ideológica de independientes y simpatizantes llevo a considerar dos hipótesis: la primera, en donde los electores no tenían claridad o posición ideológica, y segunda, donde la explicación a dichos cambios pudieran ser generados por

\footnotetext{
${ }^{1}$ Downs encontró dos limitaciones a la ideología: 1) no era lo suficientemente concreta para llevarla a la acción ya que en ella caben bastantes alternativas; 2) a los votantes les interesan acciones concretas, por lo que los partidos deben contrastar con frecuencia sus acciones con las preferencias de los votantes (DOWNS, 1957, p. 103-109).

${ }^{2}$ Las posiciones políticas son instrumento que sirven a los electores para procesar información y proporciona una estructura de análisis y valoración sobre la política que permite diferenciar conceptos de carácter político o ideológico. Las etiquetas de identidad ideológico-política refleja el conflicto entre: socialismo-estatista/capitalismo-democrático; derecha/izquierda; autoritarios/demócratas. Representan polos opuestos en temas de carácter social: normas, valores sexuales, la familia, derechos de la mujer, minorías, migración, xenofobia, movimientos ambientalistas, expresiones indigenistas (MORENO, 2003).
} 
un intenso debate entre posturas políticas confrontadas intensamente. En la idea de verificar alguna de ellas se analizó la posición política de unos y otros en el marco del proceso de desafuero.

Cuadro 2 - Ubicación ideológica de lectores y simpatizantes (\%)

\begin{tabular}{|l|c|c|c|c|c|c|}
\hline & \multicolumn{3}{|c|}{ Electores } & \multicolumn{3}{c|}{ Simpatizantes } \\
\cline { 2 - 7 } & Agosto & Septiembre & Octubre & Agosto & Septiembre & Octubre \\
\hline $\begin{array}{l}\text { Izquierda } \\
\text { Centro } \\
\text { izquierda }\end{array}$ & 14 & 21 & 16 & 12 & 14 & 13 \\
\hline Centro & 21 & 23 & 28 & 26 & 15 & 23 \\
\hline $\begin{array}{l}\text { Centro } \\
\text { derecha }\end{array}$ & 16 & 22 & 22 & 20 & 24 & 24 \\
\hline Derecha & 29 & 26 & 26 & 30 & 35 & 26 \\
\hline
\end{tabular}

Fuente: Elaboración propia con datos obtenidos del Estudio Panel sobre comportamiento electoral en Mazatlán, Sinaloa, 2004.

Contra el desafuero de AMLO en Sinaloa, el PRD realizó una fuerte movilización con el objetivo de que el diputado priísta Francisco Frías Castro, integrante de la Comisión Instructora (también sinaloense), modificará la orientación de su voto. Con la idea de saber si éstos hechos tenían algún significado para los electores sinaloenses que los llevara a tomar alguna posición relativa al tema, se les cuestionó sobre su posición de apoyo o rechazo hacia AMLO-FOX.

Sobre el apoyo, se encontró que $51 \%$ de los electores se manifestó entre de acuerdo y completamente de acuerdo con VFQ y $12 \%$ expresó una posición neutral sin que se observaran cambios al respecto. Por el contrario, con el $37 \%$ restante que expresó su apoyo a AMLO se observó un desplazamiento hacia el extremo izquierdo disminuyendo quienes se manifestaban simplemente de acuerdo (13-8\%) e incrementando los que decían estar completamente de acuerdo (24-31\%) entre agosto y septiembre. Lo anterior significa que entre los que apoyaban a VFQ el conflicto no modificó su posición inicial, mientras que los simpatizantes de AMLO los elementos a debate vertidos durante esta confrontación política los llevaron a fortalecer su posición, de manera particular con hombres adultos (Figura 1). 
Figura 1 - AMLO Y FOX

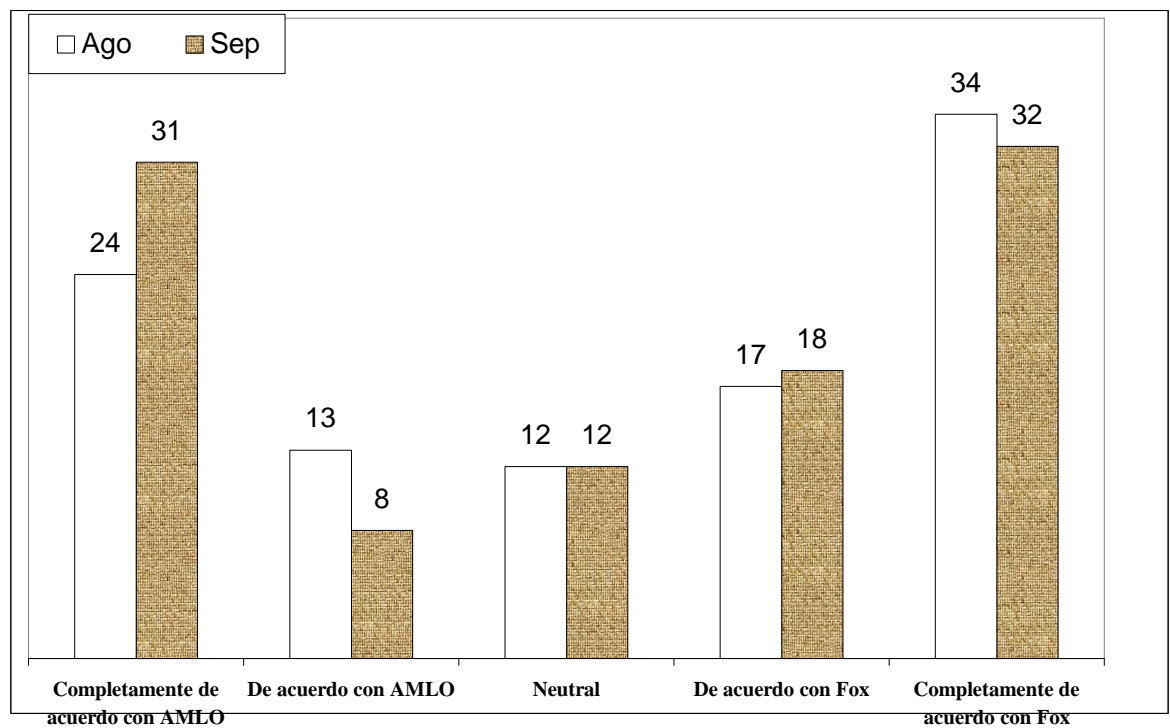

Fonte: Elaboración propia con datos obtenidos del Estudio Panel sobre comportamiento electoral en Mazatlán, Sinaloa, 2004.

El conflicto político AMLO-FOX tuvo como ataque y defensa una lucha mediática. El PRD dirigió una campaña propagandística en medios electrónicos, (televisión), que mostraba logros del gobierno de la Ciudad de México resaltando obras durante la administración de AMLO y sus programas sociales, donde Adultos Mayores, sobresalía como un distintivo de su gobierno. En contraparte, el gobierno federal desde las Secretarias de Gobernación y Desarrollo Social desplegó una campaña que persuadía sobre el respeto a la ley, logros de asistencia social, entre ellos el Programa Oportunidades. Con la idea de conocer si este conflicto político modificaba la percepción de los electores bajo un sentido programático se preguntó sobre la posición respecto a los programas Adultos Mayores (AMLO) y Oportunidades (FOX). Sin mayores cambios, el 51\% de los electores se manifestó estar entre de acuerdo/completamente de acuerdo con Oportunidades. Por el contrario, quienes se mantenían en una posición neutral y se manifestaban de acuerdo con Adultos mayores se replegaron hacia los extremos en septiembre. Lo cual significa que fortalecieron su posición programática hasta quedar completamente convencidos de su posición, mientras que quienes habían mantenido una posición neutral adoptaron un proceso de definición orientado hacia el programa Oportunidades. Es decir, que el apoyo mostrado hacia AMLO se tradujo también en un sentido programático respecto a sus programas de gobierno (Figura 2). 
Figura 2 -Adultos mayores y oportunidades

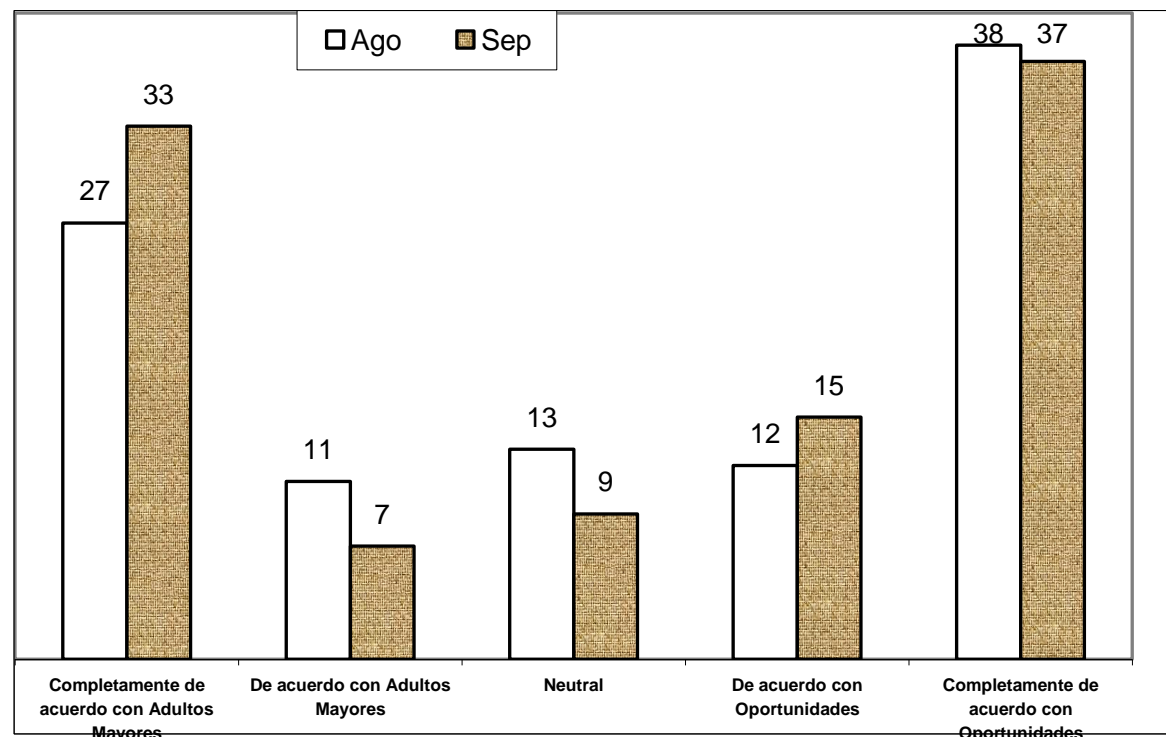

Fonte: Elaboración propia con datos obtenidos del Estudio Panel sobre comportamiento electoral en Mazatlán, Sinaloa, 2004.

Otro punto importante es la relación entre los gobernantes y gobernados. Los gobiernos de izquierda han insistido que su actividad contempla una relación más cercana con la gente. El problema se centra que en Mazatlán sola PAN y PRI tienen experiencia de gobierno. Respecto a si la autoridad debería tener mayores obligaciones con los ciudadanos, o ser éstos últimos más responsables consigo mismos, la posición aceptada fue la primera. Entre agosto y octubre, de 55-64\% de los electores se manifestaron entre a favor/completamente a favor de que el municipio fuera más responsable con los ciudadanos. Por el contrario, de 35-24\% expresó que debían ser los ciudadanos más responsables con ellos mismos. De nueva cuenta se observó que se parte de una posición ampliamente aceptada, pero además, que en el transcurso de las campañas quienes mantienen puntos de vista contrarios a este tipo de posiciones terminan de igual forma aceptándolas (Figura 3). 
Figura 3 - Responsabilidad de las autoridades

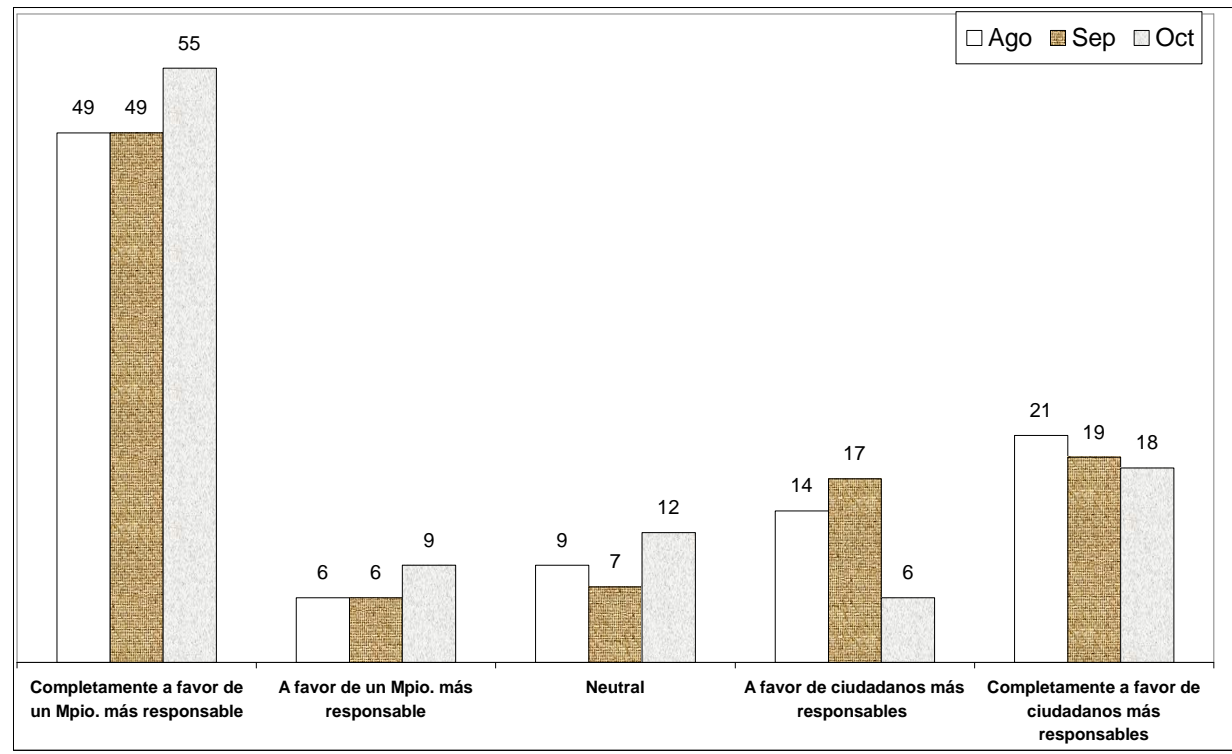

Fonte: Elaboración propia con datos obtenidos del Estudio Panel sobre comportamiento electoral en Mazatlán, Sinaloa, 2004.

La instalación de casinos fue uno de los pocos temas donde los partidos tomaron posiciones encontradas. Aunque dicho aspecto tuvo en el pasado algunos intentos fallidos, en el gobierno de VFQ el asunto cobró principal interés. El tema fue debatido en los medios por Creel (Gobernación), Derbéz (Economía) y Elizondo (Turismo), quienes dejaron clara la posición del gobierno. Siendo Mazatlán un centro turístico importante del noroeste del país y en donde podría beneficiarlos o perjudicarlos directamente, se preguntó durante septiembre y octubre la opinión respecto al tema. Quienes se manifestaban en completo desacuerdo disminuyeron de $41-25 \%$, y en desacuerdo fueron de $6-13 \%$. Aquellos que mantenían una posición neutral aumentaron de $11-18 \%$, y de completo acuerdo fueron de $27-32 \%$. Con estos datos la posición de los electores dejó ver que quienes se manifestaban completamente en desacuerdo fueron modificando su posición de manera neutral y en algunos casos hasta estar de acuerdo. Entre los simpatizantes, los panistas se encontraban sin cambios principalmente a favor de la instalación. Los priístas con una posición neutral y de acuerdo con la medida se desplazaron hacia la izquierda, variando del acuerdo a una posición neutral y de esta última al desacuerdo. Los perredistas que manifestaban acuerdo con la medida, neutrales y en desacuerdo, modificaron su posición hacia un punto neutral. Aunque el tema no fue tratado en las campañas llama la atención los cambios entre los electores, y en el desplazamiento en mayor medida de priístas y perredistas hacia el centro de la escala (Figura 4). 


\section{ARTIGOS}

Figura 4 - Instalación de casinos

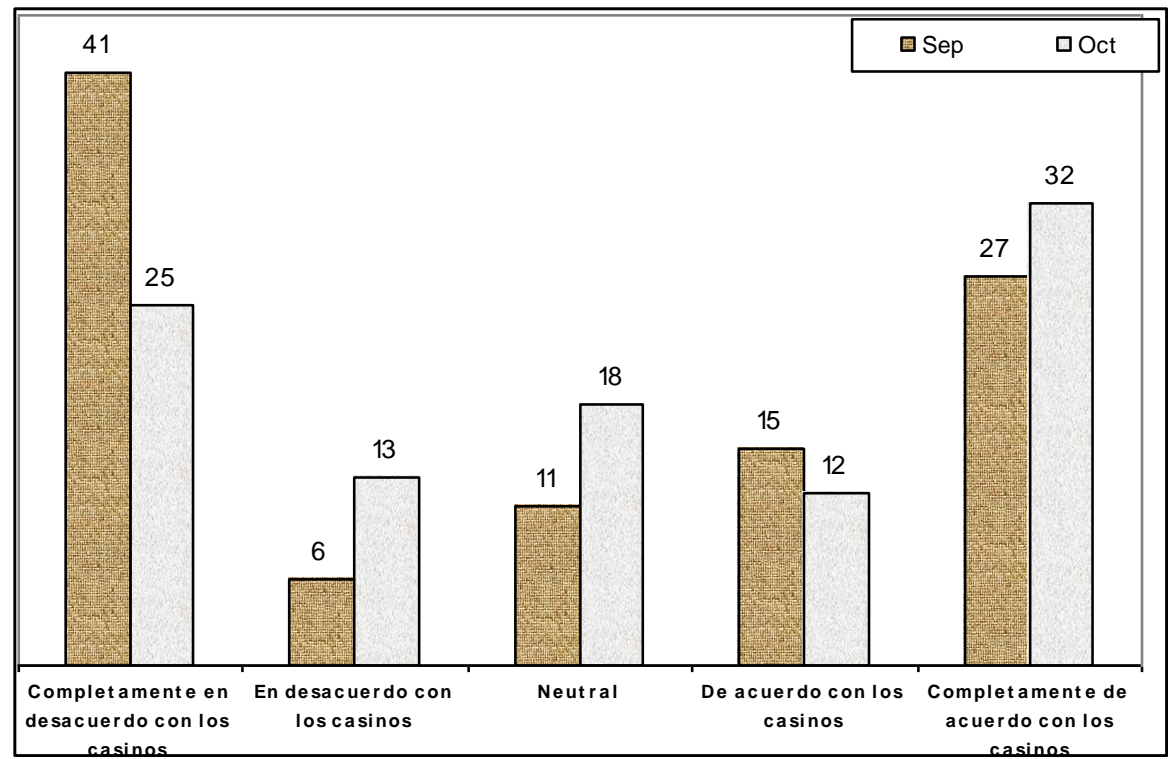

Fonte: Elaboración propia con datos obtenidos del Estudio Panel sobre comportamiento electoral en Mazatlán, Sinaloa, 2004.

¿Guardan coherencia estas posiciones entre sí? ¿Tuvieron algo que ver éstas opiniones con la decisión del voto? Al analizar estadísticamente la relación entre dichas posiciones se encontró que las de mayor coherencia fueron el apoyo a líderes políticos y sus programas de gobierno, así como la responsabilidad de los gobiernos con los ciudadanos. Sin embargo, en todos los casos los niveles de significancia mostraron solamente una relación media positiva. Con ello se entiende que los cambios en la decisión del voto no pasaron por consideraciones de este tipo. Es decir, las posiciones políticas de los electores no fueron condicionantes en su decisión electoral (Cuadro 3). 
Cuadro 3 - Coherencia entre posiciones y relación con el voto

\begin{tabular}{|c|c|c|c|c|c|c|}
\hline \multirow{2}{*}{$\begin{array}{l}\text { Coherencia entre } \\
\text { posiciones políticas }\end{array}$} & \multicolumn{2}{|c|}{ Agosto } & \multicolumn{2}{|c|}{ Septiembre } & \multicolumn{2}{|c|}{ Octubre } \\
\hline & $\begin{array}{c}\mathrm{rde} \\
\text { pearson }\end{array}$ & Sig. & $\begin{array}{c}\text { rde } \\
\text { pearson }\end{array}$ & Sig. & $\begin{array}{c}\mathrm{rde} \\
\text { pearson }\end{array}$ & Sig. \\
\hline $\begin{array}{l}\text { AMLO-FOX/Adultos Mayores- } \\
\text { Oportunidades }\end{array}$ & 618 & .000 & 671 & .000 & -- & -- \\
\hline $\begin{array}{l}\text { Servidores Públicos/Responsabilidad } \\
\text { Gobierno }\end{array}$ & .573 & .000 & 629 & .000 & .521 & .000 \\
\hline AMLO-FOX/Responsabilidad Gobierno & .287 & .000 & .252 & .000 & -- & -- \\
\hline $\begin{array}{l}\text { AMLO-FOX/ Ingreso Servidores } \\
\text { Públicos }\end{array}$ & .281 & .000 & .329 & .000 & --- & -- \\
\hline $\begin{array}{l}\text { AMLO-Oportunidades/Ingreso } \\
\text { Servidores Públicos }\end{array}$ & .243 & .000 & .310 & .000 & -- & -- \\
\hline $\begin{array}{l}\text { Izquierda-derecha/ Responsabilidad } \\
\text { Gob. }\end{array}$ & .239 & .000 & .219 & .002 & 163 & .037 \\
\hline \multicolumn{7}{|l|}{ Posición política y Voto } \\
\hline Posición AMLO y FOX & -.112 & .091 & -.069 & .316 & -- & -- \\
\hline Adultos mayores- oportunidades & -.081 & .222 & .021 & .761 & -- & -- \\
\hline Izquierda y derecha & -.090 & .182 & -.165 & .017 & -.077 & .323 \\
\hline Responsabilidad del gobierno & .175 & .008 & .068 & .332 & -.045 & .543 \\
\hline Casinos & & -- & -.038 & .186 & -.043 & .540 \\
\hline
\end{tabular}

Fonte: Elaboración propia con datos obtenidos del Estudio Panel sobre comportamiento electoral en Mazatlán, Sinaloa, 2004.

En tal sentido, se opto por indagar sobre las evaluaciones retrospectivas y prospectivas de los electores a fin de conocer si dichos elementos representaban alguna utilidad para su voto.

\section{Beneficios (utilidad) del voto: Evaluación retrospectiva/situación económica}

Como parte de la evaluación retrospectiva, particularmente en lo relativo al análisis de la situación económica, a finales de agosto de $2004 \mathrm{El}$ Debate publicó datos de una encuesta relativos a la situación económica del país, la personal y la responsabilidad del gobierno federal. Sobre el primer, $51 \%$ dijo mantenerse igual que a principios del año, 30\% había empeorado y $15 \%$ expresó mejoría. En la situación personal comparada con un año de anterioridad, $33.4 \%$ manifestó mejoría, $49.5 \%$ era igual y $17 \%$ peor. Sobre la forma cómo las autoridades habían manejado la economía, $24 \%$ se decía entre totalmente/algo de acuerdo, 55\% totalmente/algo en desacuerdo, $21 \%$ indiferente. Además de mostrar la insuficiencia de los ingresos familiares para vivir, las principales inquietudes eran los problemas generados para cubrir las deudas y la imposibilidad de destinar alguna cantidad al ahorro ${ }^{3}$. ¿La

${ }^{3}$ En lo relativo a los ingresos familiares expresaban que, no le alcanzaba ni para vivir (31\%), apenas para vivir (46\%), le alcanzaba para vivir bien (23\%). Como preocupaciones económicas surgían la inseguridad (35\%), economía y desempleo (sendos $18 \%$ ), educación de los hijos $(13 \%)$, bajos salarios (10\%). Sobre la posibilidad de cubrir deudas, $44 \%$ dijo tener problemas, 
percepción sobre la situación económica será la misma entre los electores aunque estos tengan diferentes características sociodemógráficas y políticas? ¿Pueden las campañas electorales modificar la percepción de los electores en cuanto a la situación económica en que se encuentran?

Para responder dichas interrogantes, se indagó sobre la percepción de los electores respecto a su situación económica en tres niveles. Primero, sobre la situación económica municipal actual (SEMA), y se les pidió que la valorarán en relación a un año de anterioridad (SECA). Considerando que no sufre grandes cambios en tiempos tan cortos, se preguntó sobre su situación económica personal (SEP). Para el análisis se tomaron dos vertientes: A) la percepción de la situación económica en forma agregada a través de las características sociodemográficas con la idea de conocer si existían o no diferencias de percepción; B) la simpatía partidaria, considerando que podría mantener una relación más fuerte con la SE. En la primera, se consideró la edad, escolaridad e ingreso como las más probables a encontrar cambios de percepción. Con los jóvenes con mayor escolaridad e ingreso, la percepción cambio negativamente. En los adultos con menor escolaridad e ingreso la percepción tuvo una orientación positiva. Analizando a través de la edadSEMA quienes consideraban que había mejorado aumentaron (34-53\%) y empeorado disminuyeron (63-37\%). Sobre la SEP los que consideraban que mejoraba disminuyeron (53-31\%) y empeoraba aumentaron (47-68\%). Con la escolaridad-SEP solamente se observó un cambio de quienes consideraban que había empeorado (47-37\%). Mientras en el ingreso únicamente se encontró una disminución (64-58\%) de quienes consideraban que la SEMA había empeorado.

Al analizar la SE mediante la simpatía partidaria se encontró que sólo con ellos se cumple el principio de apoyar al partido que gobierna cuando la situación es favorable y la preferencia hacia otro partido cuando resulta perjudicial. Es decir, los panistas y perredistas consideraban que la SE había empeorado, mientras los prí́stas expresaban mejoría. De esta manera, los panistas que consideraban la SEMA negativa crecieron (33-37\%) y disminuyó con prí́stas $(23-18 \%)$, y perredistas $(12-9 \%)$. Por el contrario, entre los que la consideraban positiva con panistas $(10 \%)$, prístas $(20 \%)$, y perredistas (2$7 \%$ ) durante la campaña. Con la SEP los panistas que manifestaron mejoría disminuyeron (27-17\%), y que había empeorado aumentaron (15-21\%). Con los priístas el principal cambio se observó con aquellos que expresaban que había empeorado (25-13\%). Respecto a la SECA, se observaron cambios con los priístas que consideraban que la situación estaba igual (21-13\%) y peor (21-12\%). Después de saber que electores con diferencias sociodemográficas y simpatía partidaria expresaron distintos cambios en su percepción sobre la $\mathrm{SE}$, restó conocer si la percepción tuvo relación con el voto.

En la relación SE-voto para presidente municipal se encontró que para Higuera y Granados la intención de voto mayoritario fue de aquellos que

$34 \%$ no tener problema, $22 \%$ dijo no saber (El Debate, Encuesta sobre economía familiar, 23 de agosto de $2004,2^{\mathrm{a}}$ ). 
consideraban la SEMA como negativa. Para Higuera representaban $30 \%$, con Granados $19 \%$ al final de la campaña. Por el contrario, quienes consideraban positiva la situación disminuyeron de $21-10 \%$ y $10-5 \%$, respectivamente. Con Durán cuyos electores mantenían una percepción negativa, al final de las campañas se modificó de forma positiva. Al analizar la intención de voto de acuerdo a la SEP, se observó que los posibles votantes de Higuera se encontraban principalmente en quienes consideraban mejoría, pero disminuyeron (33-20\%) hasta coincidir con quienes manifestaban que había empeorado. Para Granados sus posibles votantes se encontraron en forma equilibrada en quienes expresaban mejoría (15-10\%) y que había empeorado $(12-8 \%)$. Para Durán, sus votantes se encontraban, entre aquellos cuya situación personal era negativa, pero se modificó de manera contraria la final de las campañas. Sobre la SECA para Higuera no se observaron cambios, mientras con Ganados quienes consideraban que la situación había empeorado disminuyeron (9-6\%) al igual que con Durán (5-2\%). Los anteriores datos muestran que la percepción sobre la situación económica de los electores siendo esta positiva o negativa no favoreció o perjudicó a ninguno de los candidatos, al no expresar una clara intención de voto a favor de alguno de los candidatos - a excepción de los simpatizantes - pero falta conocer la evaluación de los gobiernos en turno, como un segundo elemento de análisis retrospectivo (Cuadro 4).

Cuadro 4 - Situación Económica y desempeño del gobierno

\begin{tabular}{|c|c|c|c|c|c|c|c|c|c|c|c|c|c|}
\hline \multirow{3}{*}{ Candidatos } & \multicolumn{6}{|c|}{$\begin{array}{c}\text { Situación económica municipal } \\
\text { (SEMA) }\end{array}$} & \multirow{3}{*}{ Candidatos } & \multicolumn{6}{|c|}{$\begin{array}{c}\text { Desempeño del gobierno } \\
\text { estatal }\end{array}$} \\
\hline & \multicolumn{3}{|c|}{\begin{tabular}{|l|} 
Positiva \\
\end{tabular}} & \multicolumn{3}{|c|}{ Negativa } & & \multicolumn{3}{|c|}{ Positivo } & \multicolumn{3}{|c|}{ Negativo } \\
\hline & Ago. & Sep. & Oct. & Ago & . 5 Sep & . 1 Oct. & & Ago. & Sep. & Oct. & Ago. & Sep. & Oct. \\
\hline Higuera & 21 & 20 & 10 & 32 & 35 & 30 & Aguilar & 7 & 10 & 23 & 14 & 16 & 13 \\
\hline Gran & & & 5 & 17 & & & & 16 & & 22 & 23 & & 15 \\
\hline \multirow[t]{2}{*}{ Durán } & 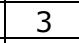 & 5 & 1 & 7 & & 15 & & & & 5 & 7 & & 6 \\
\hline & \multicolumn{6}{|c|}{$\begin{array}{c}\text { Situación económica personal } \\
\text { (SEP) }\end{array}$} & & \multicolumn{6}{|c|}{ Gobierno municipal } \\
\hline \multirow[b]{2}{*}{ Candidatos } & \multicolumn{3}{|c|}{ Mejorado } & \multicolumn{3}{|c|}{ Empeorado } & & \multicolumn{3}{|c|}{ Positivo } & \multicolumn{3}{|c|}{ Negativo } \\
\hline & Ago. & Sep. & Oct. & Ago. & Sep. & Oct. & Candide & Ago. & Sep. & Oct. & Ago. & Sep. & Oct. \\
\hline & 33 & & & & & & & 20 & & 24 & 24 & & 26 \\
\hline Gran & & & & & & & & 10 & & 16 & 10 & & 10 \\
\hline \multirow[t]{2}{*}{ Durán } & 4 & 6 & 6 & 7 & 10 & 3 & & 2 & & 8 & & & 5 \\
\hline & \multicolumn{6}{|c|}{$\begin{array}{c}\text { Situación económica comparada } \\
\text { (SECA) }\end{array}$} & & \multicolumn{6}{|c|}{ Gobierno municipal } \\
\hline \multirow{2}{*}{ Candidatos } & \multicolumn{3}{|c|}{\begin{tabular}{|c|} 
Mejor \\
\end{tabular}} & \multicolumn{3}{|c|}{ Peor } & & \multicolumn{3}{|c|}{ Positivo } & \multicolumn{3}{|c|}{ Negativo } \\
\hline & Ago. & Sep. & Oct. & Ago. & Sep. & Oct. & & Ago. & Sep. & Oct. & Ago. & Sep. & Oct \\
\hline & 6 & 6 & 6 & 17 & 17 & 14 & & 17 & & 19 & 10 & & 27 \\
\hline & 3 & 4 & & 9 & & & & 13 & & 29 & 21 & & 13 \\
\hline Durán & -- & -- & -- & 5 & 4 & 2 & perredistas & 6 & 6 & 3 & 8 & 8 & 3 \\
\hline
\end{tabular}

Fonte: Elaboración propia con datos obtenidos del Estudio Panel sobre comportamiento electoral en Mazatlán, Sinaloa, 2004.

De igual manera, las elecciones se presentan regularmente como una forma de rendición de cuentas de los partidos políticos. Esta sigue la misma evaluación de la SE, es decir, respaldar al gobierno si su actuación fue buena, 
o de lo contrario votar por una opción distinta. Bajo esta premisa se preguntó sobre el desempeño que habían tenido el gobierno estatal y municipal y posteriormente se relacionó con la intención de voto. Sobre el gobierno estatal, la evaluación positiva creció (32-54\%) y negativa disminuyó (49$44 \%$ ). Si bien es cierto, quienes cambiaron su percepción sobre el desempeño del gobernador de manera satisfactoria crecieron 22 puntos porcentuales, éstos no vendrían de quienes mantenían una percepción negativa, sino de aquellos que expresaban desconocimiento (19-4\%). Con el cruce entre evaluación del gobierno estatal-Voto para gobernador, se encontró que los posibles votantes de Félix que calificaban positivamente el desempeño aumentaron (16-22\%), y negativamente disminuyeron (23-15\%). Con Aguilar quienes evaluaban positivamente al gobierno aumentaron (7-23\%) y negativamente se mantuvieron en la misma proporción. Los electores con la intención de voto a favor de Audómar no mostraron cambios significativos.

Al realizar el cruce entre voto presidente municipal-evaluación gobierno municipal se encontró algo distinto entre independientes y simpatizantes. Con los primeros no se observaron cambios drásticos respecto en la evaluación del gobierno, ni que ésta generara algún tipo de influencia sobre el voto. La calificación positiva sobre el desempeño del gobierno municipal fueron: Higuera (20-24\%), Granados (10-16\%) y Durán (1-8\%.) y negativa fue para Higuera (24-26\%), Granados (10\%), Durán (8-5\%). Los que manifestaban desconocimiento disminuyeron (10-1\%), Higuera (7-2\%), durante los meses de agosto a octubre.

Con los simpatizantes la intención de voto si tuvo relación con el desempeño del gobierno. Dado que el gobierno municipal al momento de la elección era priísta, se pensó que serían ellos quienes calificarían mejor el desempeño y panistas y perredistas darían una peor calificación. La tendencia fue la esperada, entre los priístas a medida que se desarrollaba la campaña modificaron positivamente su percepción sobre el desempeño del gobierno municipal. Quienes consideraban un desempeño positivo crecieron (13-29\%) y negativo disminuyeron (21-13\%). Con los panistas, el desempeño positivo fue $17-19 \%$, negativo $10-27 \%$. En tal virtud, los datos analizados muestran entre los simpatizantes una evaluación positiva y negativa sobre el desempeño del gobierno municipal a manera de apoyo y rechazo, lo cual indica que la intención del voto y el desempeño del gobierno en turno fue un factor que orientó la decisión del voto solamente de los simpatizantes, pues en los independientes no generó ningún tipo de influencia.

\subsection{Comparación y orden de preferencias: Evaluación prospectiva/EI mejor gobierno}

La comparación es una de las características más frecuentes entre los electores estratégicos. Es uno de los aspectos más importante entre el conjunto de evaluaciones prospectivas, ya que pone de manifiesto beneficios que generan los candidatos que compiten. En la idea de conocer la evaluación y el nivel de aceptación o rechazo para los candidatos a gobernador y 
Ayuntamiento se preguntó cómo sería el gobierno de cada uno de ellos en comparación con los gobiernos en turno. En la elección a gobernador, en la evaluación positiva $63 \%$ expresó que Félix podía hacer mucho/algo más que el gobierno de Millán, mientras $26 \%$ que haría menos/mucho menos. Para Aguilar, $67 \%$ consideraban que podía hacer mucho/algo contra $25 \%$ que manifestaba lo contrario. Con Audómar la evaluación tanto positiva y negativa osciló entre $40 \%$, mientras $20 \%$ restante expresó completo desconocimiento. Lo anterior muestra que los electores que se expresaban de manera positiva como negativa para Aguilar y Felix fueron semejantes en cada uno de los aspectos evaluados. Con los candidatos al Ayuntamiento, para Higuera la evaluación fue predominantemente positiva. Más de un tercio de los encuestados expresaron que dicho candidato podría hacer algo más que la administración en turno, mientras una proporción mayor mantuvo una expectativa aún más favorable considerando que podría realizar mucho más de lo realizado hasta ese momento. Para Granados quienes consideraban que podía dirigir un mejor gobierno decrecieron ligeramente. Si bien la evaluación fue positiva, al igual que con Higuera, se consideraba que solamente podría hacer "algo", pero no "mucho más." Para Durán la evaluación fue negativa, solo $30 \%$ expresó que podría hacer algo más, $50 \%$ lo valoró negativamente, un $15 \%$ desconocía la posible forma de cómo gobernaría.

Resulta claro que, si bien la comparación se realizó entre los candidatos y el gobierno municipal en turno, el resultado mostraba la distancia existente entre ellos. No obstante, en la idea de conocer la relación que tenía su evaluación con el voto, se cruzaron las variables voto presidente municipal-evaluación prospectiva de los candidatos. De esta manera, al preguntarles a los electores a favor de Higuera, se encontró que de $39 \%$ de sus preferencias, $37 \%$ expresaban que podría hacer mucho/algo más que el gobierno en turno. Con aquellos a favor de Granados, del $37 \%$ en su preferencia, $26 \%$ manifestaban que haría mucho/algo más que el gobierno municipal. Con ello se observa que en relación con Higuera y Granados la orientación mantuvo cierto equilibrio entre las evaluaciones positivas y negativas.

Se les pidió también a los electores que realizaran una comparación entre los candidatos en la idea de definir un orden de preferencias y compararlas con las opciones competitivas. Toda decisión racional que cumple con los principios de comparabilidad y transitividad da como resultado un principio de ordenación que permite que un individuo tome un conjunto de objetos y los coloque en cierto orden, del más alto al más bajo (y empates) que refleja gustos y valores personales. La racionalidad se vincula tanto con la capacidad para ordenar como la aptitud para elegir el primer lugar del orden (SHEPSLE y BONCHEK, 2005). Se cuestionó sobre sus principales opciones en la contienda y se encontró que el orden de preferencias mantenía cierta estabilidad. Para los panistas sería PAN/PRI/PRD; los priístas PRI/PAN/PRD; perredistas PRD/PAN/PRI y petistas PT/PRD/PRI. En ello se observa los electores del PAN y PRI el orden y la comparación de sus preferencias mostró una secuencia transitiva y perfectamente comparable. Con los del PRD y PT se 
produjo un orden de preferencias incoherentes al mostrar intransitividad. En sentido estricto, el orden de preferencias sirve para explicar los cambios en el voto, sin embargo en la elección para la gubernatura y Ayuntamiento se observó que electores a favor del PRD y PT reorientaron su voto al margen de su orden de preferencia. Dichas decisión pueden explicarse por motivo de las alianzas partidarias, en donde todas las opciones de su preferencia no tienen posibilidades de triunfo por lo que optan por otra opción con mayor posibilidad de ganar. Pero esta reorientación tuvo como principal fundamento los posibles beneficios sobre el triunfo de alguno de los dos candidatos restantes, la cual debe reflejarse en las tendencias electorales, el momento en la decisión del voto y el resultado electoral (Cuadro 5).

Cuadro 5 - Orden de preferencias de los electores en Mazatlán, Sinaloa (\%)

\begin{tabular}{|c|c|c|c|}
\hline Orden de preferencias & agosto & septiembre & Octubre \\
\hline Ninguno & 18 & 14 & 13 \\
\hline 1)PAN 2)Abstención & 2 & 3 & 2 \\
\hline $\begin{array}{lll}\text { 1)PAN 2)PRD 3)PRI } & \text { 4). PT-ABS }\end{array}$ & 16 & 12 & 10 \\
\hline 1)PAN 2)PRI 3)PRD-PT-ABS-PVEM & 24 & 19 & 26 \\
\hline 1)PAN 2)PT $\quad$ 3)PRD-PRI-PVEM & 5 & 7 & 3 \\
\hline Total & 37 & 41 & 41 \\
\hline 1)PRI 2)Abstención & 2 & 1 & 1 \\
\hline 1)PRI 2)PRD 3)PAN-PT-C-PVEM & 8 & 6 & 9 \\
\hline 1)PRI 2)PAN 3)PRD-PT-ABS & 13 & 15 & 17 \\
\hline 1)PRI 2)PT & 1 & 1 & 4 \\
\hline Total & 24 & 23 & 31 \\
\hline 1)PRD 2)Abstención & 1 & 1 & - \\
\hline 1)PRD 2$) P R I \quad$ 3)PAN-PT-ABS & 7 & 9 & 4 \\
\hline 1)PRD 2)PAN 3)PRI-PT-PVEM & 4 & 4 & 6 \\
\hline $\begin{array}{lll}\text { 1)PRD } & \text { 2)PT } & \text { 3)PAN-PRI-PVEM-C }\end{array}$ & 3 & 3 & - \\
\hline 1)PRD 2)CONV 3)PVEM & 1 & - & - \\
\hline Total & 16 & 17 & 10 \\
\hline 1)PT 2)PRD 3)PAN-PRI & 3 & 3 & - \\
\hline 1)PT 2)PRI 3)PAN-ABS-PRD & 1 & 2 & - \\
\hline 1)PT 2)PAN 3)PRI-ABS & 1 & 1 & 5 \\
\hline Total & 5 & 5 & 5 \\
\hline
\end{tabular}

Fuente: Elaboración propia con datos obtenidos del Estudio Panel sobre comportamiento electoral en Mazatlán, Sinaloa, 2004.

\section{Condiciones de competencia}

En las campañas a gobernador la competencia se centró en Aguilar y Félix. El primero inició con el $51 \%$ de preferencias, mostrando una tendencia cíclica con un decrecimiento de alrededor de 4 puntos porcentuales. Félix con una tendencia creciente inició con $23 \%$ de intención y alcanzó $46 \%$ de los votos (crecimiento del 100\%). En Mazatlán fue el caso contrario, Félix inicio con $45 \%$ de preferencias concluyó en $48 \%$ de los votos. Aguilar con $24 \%$ en la intención alcanzó $43 \%$ del resultado (incrementó de 19 puntos 
porcentuales). En lo que respecta a Audómar mostró una tendencia estatal (13-4\%) y municipal (13-12\%) a la baja.

Para la elección del Ayuntamiento, los datos de El Debate mostraron una competencia muy cerrada entre Higuera y Granados. Higuera alcanzó su máxima intención de voto en la primera semana de septiembre. Aunque fue disminuyendo en meses posteriores su resultado electoral fue ligeramente mayor a su intención inicial de voto, por lo que se estima su campaña no generó más de lo que tenía al principio. Con Granados la intención inicial era de $40 \%$, cayó entre el $25-28 \%$ durante el resto de la campaña. Su recuperación se observó únicamente con el resultado electoral. En el caso de Durán la intención de voto mostró un incremento gradual de agosto a octubre, para descender drásticamente con el resultado electoral. Los datos del panel mostraron una intención inicial de voto de 54\% para Higuera, 27\% Granados y $11 \%$ Durán. Pero la diferencia en el resultado fue de casi tres puntos porcentuales a favor de Higuera contra Granados. Con Higuera y Durán el resultado electoral mostró una caída de 6 puntos porcentuales en relación a su intención de voto inicial, mientras Granados incrementó 20 puntos porcentuales con el resultado electoral.

La elección de diputado en el distrito XIX mostró que a partir de agosto se configuró una competencia entre Feltón y Tirado, seguida de Pasos. La intención de voto no sufrió grandes cambios durante los dos primeros meses de campaña, pero una encuesta de Noroeste a principios de noviembre mostró cambios sustanciales en relación a los datos obtenidos por la tercera ronda del panel. Aunque los datos de Noroeste mantenían a Felton como el mejor posicionado, para Tirado la intención del voto creció considerablemente y Pasos se desplomó de manera drástica. Felton logró el triunfo, pero su campaña significó un incremento de 6 puntos y 15 puntos para Tirado. En el distrito XX, Vega fue la mejor posicionada, seguida de Figueroa y con menos de 10 puntos porcentuales Carrillo y Benítez. Vega inició con 54\% de intención pero cayó al $37 \%$ en el resultado electoral (17 puntos), perdiendo la elección. Figueroa inició con $20 \%$ y alcanzó el $40 \%$ de los votos en noviembre (creció $100 \%$ ) ganando la elección. Carrillo fue del 9-4\% de la votación total, mientras que Osuna fue del $9-17 \%$ de la votación total (Cuadro 6). ¿A que se debieron estos resultados? 
Cuadro 6 - Tendencias electorales en las elecciones de Mazatlán en 2004

\begin{tabular}{|c|c|c|c|c|c|c|c|}
\hline \multirow{2}{*}{ Debate } & \multicolumn{3}{|c|}{ Gobernador } & \multirow{2}{*}{ Panel } & \multicolumn{3}{|c|}{ Gobernador (Mazatlán) } \\
\hline & Aguilar & Félix & Audomar & & Aguilar & Félix & Audomar \\
\hline Agosto & 51.3 & 22.8 & 12.8 & $\begin{array}{l}1 \text { Ronda } \\
\text { (ago.) }\end{array}$ & 24 & 45 & 14 \\
\hline Septiembre & 53 & 31 & 13 & $\begin{array}{c}2 \text { Ronda } \\
\text { (sep.) }\end{array}$ & 26 & 46 & 15 \\
\hline Octubre & 46.5 & 28.1 & 5.9 & $\begin{array}{c}3 \text { Ronda } \\
\text { (oct.) }\end{array}$ & 42 & 40 & 12 \\
\hline Noviembre & 53 & 41 & 5 & \multirow{2}{*}{ Resultado } & \multirow{2}{*}{43.2} & \multirow{2}{*}{48.6} & \multirow{2}{*}{2.4} \\
\hline Resultado & 47 & 46 & 4.1 & & & & \\
\hline \multirow{2}{*}{ Panel } & \multicolumn{3}{|c|}{ Presidente } & \multirow{2}{*}{ Panel } & \multicolumn{3}{|c|}{ Presidente } \\
\hline & Higuera & Granados & Durán & & Higuera & Granados & Durán \\
\hline Agosto & 44.7 & 42.3 & 12 & $\begin{array}{l}1 \text { Ronda } \\
\text { (ago.) }\end{array}$ & 54 & 27 & 11 \\
\hline Septiembre & 57.7 & 28.9 & 8.3 & $\begin{array}{c}2 \text { Ronda } \\
\text { (sep.) }\end{array}$ & 53 & 26 & 13 \\
\hline Octubre & 53.5 & 24.6 & 11.4 & $\begin{array}{l}3 \text { Ronda } \\
\text { (oct.) }\end{array}$ & 39 & 37 & 11 \\
\hline Noviembre & 43.7 & 28.3 & 14.6 & \multirow{2}{*}{ Resultado } & \multirow{2}{*}{47.8} & \multirow{2}{*}{44.6} & \multirow{2}{*}{5.3} \\
\hline Resultado & 47.8 & 44.6 & 5.3 & & & & \\
\hline \multirow{2}{*}{ Panel } & \multicolumn{3}{|c|}{ Diputado XIX } & \multicolumn{4}{|c|}{ Diputado XX } \\
\hline & Felton & Tirado & Pasos & Vega & Figueroa & Osuna & Carrillo \\
\hline $\begin{array}{c}1 \text { Ronda } \\
\text { (ago.) }\end{array}$ & 39 & 27 & 21 & 53 & 20 & 9 & 9 \\
\hline \begin{tabular}{|c|}
$\begin{array}{c}2 \text { Ronda } \\
\text { (sep.) }\end{array}$ \\
\end{tabular} & 43 & 30 & 20 & 54 & 28 & 8 & 7 \\
\hline 3 Ronda (oct.) & 37 & 26 & 23 & 40 & 32 & 17 & 4 \\
\hline \begin{tabular}{|c|}
$\begin{array}{c}\text { Noroeste } \\
\text { (Nov.) }\end{array}$ \\
\end{tabular} & 38.8 & 33 & 14 & 32 & 33.3 & 17.3 & 5.3 \\
\hline Resultado & 45.26 & 41.86 & 6.49 & 37.59 & 40.29 & 15.9 & 4.24 \\
\hline
\end{tabular}

Fonte: Elaboración propia con datos obtenidos del Estudio Panel sobre comportamiento electoral en Mazatlán, Sinaloa, 2004.

La respuesta puede encontrase en el momento en que se tomó la decisión sobre el voto. Los datos de El Debate, distinguen una decisión muy valorada entre las opciones políticas de la elección al Ayuntamiento. Aún al momento de aplicar la última de sus encuestas - octubre -, 14\% manifestó votar por el partido de siempre, casi un tercio expresó haber decidido con tres ó más meses de anterioridad, $24 \%$ dijo decidir su voto entre el último mes y día de la encuesta, un tercio expresó no haber decidido hasta ese momento su voto. Por otra parte, las tendencias del panel muestran que un candidato muy posicionado tendrá mayor dificultad para incrementar la intención de voto a su favor, ya que parte de un máximo alcanzado. Además, se observa una caída de la intención de voto a favor del tercer candidato, lo que da a entender que el proceso de manifestación del voto - a diferencia de El Debate - se ve materializado luego de una valoración sistemática entre los candidatos 
que compiten. Pero más allá de estos elementos, los datos del panel muestran en sus tendencias un proceso tardío en la decisión del voto durante el último mes y medio de la campaña.

Al cuestionarlos sobre el momento en que habían tomado su decisión en cada una de las elecciones resaltan al menos tres aspectos: 1) 30\% de los encuestados no quiso responder a la pregunta, o no votó; 2) una proporción similar expresó haber decidido durante los primeros meses de la campaña; 3) el tercio restante dijo haber tomado su decisión desde el último mes hasta el día de la elección. Sin embargo, se observa que la decisión electoral fue un proceso tardío y diferido en las elecciones. Lo cual significa que si un elector decidió votar por algún candidato al Ayuntamiento su voto para gobernador o diputado local estuvo sujeto a otro tipo de valoraciones y momento en su definición. De esta forma, mientras $40 \%$ expresó haber decidido durante los primeros meses de campaña para el Ayuntamiento, 33\% en la elección de gobernador 32\% para diputado en el distrito XIX, y $29 \%$ en el XX. En lo que respecta al tiempo cercano como fueron los últimos 15 días anteriores al la elección, para el Ayuntamiento $12 \%$ tomó su decisión en éste momento, cifra que aumentó a $15 \%$ en la elección a gobernador, $18 \%$ para diputado en el distrito XIX, y $21 \%$ en el distrito XX (Cuadros 6-7).

Cuadro 7 - Momento en la decisión del voto por elección (\%)

\begin{tabular}{|l|c|c|c|c|}
\hline \multirow{2}{*}{ Momento de la decisión } & \multicolumn{4}{|c|}{ Elecciones } \\
\cline { 2 - 5 } & Gobernador & $\begin{array}{c}\text { Presidente } \\
\text { Municipal }\end{array}$ & $\begin{array}{c}\text { Diputado } \\
\text { Local XIX }\end{array}$ & $\begin{array}{c}\text { Diputado } \\
\text { Local XX }\end{array}$ \\
\hline El día de la elección & 5 & 4 & 7 & 8 \\
\hline En las últimas dos semanas & 10 & 8 & 11 & 13 \\
\hline En el ultimo mes & 19 & 21 & 19 & 23 \\
\hline En los últimos tres meses & 33 & 38 & 32 & 29 \\
\hline Total & 71 & 71 & 70 & 73 \\
\hline $\begin{array}{l}\text { No votó (no quisieron } \\
\text { responder) }\end{array}$ & 29 & 29 & 30 & 27 \\
\hline Total & $\mathbf{1 0 0}$ & $\mathbf{1 0 0}$ & $\mathbf{1 0 0}$ & $\mathbf{1 0 0}$ \\
\hline
\end{tabular}

Fuente: Cuarta ronda del panel, poselectoral.

Ahora bien, ¿el cambio en la decisión del voto en un elector es algo que pueda verse de manera simple? Con la finalidad de conocer las causas que motivaron los cambios en el voto, se preguntó si eran posibles dichos cambios, partiendo del entendido que al avanzar la campaña los electores convencidos de votar por el candidato de su preferencia lo expresarían firmemente, mientras los de intención débil harían lo contrario. En la elección a gobernador se encontró que la mayoría de electores fieles estaban con Félix, pero con una disminución tanto de quienes expresaban la completa seguridad de cambiar su voto, como la posibilidad de hacerlo. Lo cual significa que sus electores afianzaron su intención de voto. Aguilar logró incrementar la proporción de electores fieles y de quienes expresaban la completa seguridad de cambiar su voto y posibilidad de hacerlo. Para Audómar a pesar de que su intención de voto fue disminuyendo se observó un afianzamiento en sus 
electores fieles y una disminución de los seguros y posibles de cambiar su voto. Sobre los que manifestaban que sus candidatos podían perder, o definitivamente iban a perder con Félix quienes expresaban seguridad de triunfo disminuyeron (17-10\%) y crecieron quienes pensaban que podían ganar (23-29\%). Con Aguilar crecieron quienes expresaban mucha seguridad de triunfo $(8-10 \%)$ y que podía ganar (12-27\%). Lo cual lleva a nuevas interrogantes, ¿Cuando la principal opción (candidato o partido) de un elector aparezca sin alguna posibilidad de triunfo cambiarán su voto a otro candidato con mayores posibilidades? En la elección al Ayuntamiento se observó algo semejante, Higuera mantuvo de manera creciente al electorado fiel al final de la campaña, mientras disminuyeron los que cambiarían su voto. Granados incrementó su electorado fiel y disminuyeron los muy seguros y posibles de cambiar su voto. Con Durán los principales cambios fueron entre quienes mantenían la posibilidad de cambiar su voto al mantenerse en una tendencia creciente durante la campaña. Con ello, las tendencias analizadas y el momento en que los electores toman su decisión electoral muestran el resultado de un claro proceso de decisión.

La comparación de los resultados electorales en cada uno de los distritos muestra cambios importantes. En el distrito XIX, Félix tuvo una votación mayor que sus compañeros de partido a la presidencia municipal y diputación local. En el PRI, Granados para el Ayuntamiento, obtuvo una votación ligeramente mayor que los otros candidatos de su partido para gobernador y diputado local. Para el PRD, PT y Convergencia sus mayores votaciones se encuentran entre los candidatos a diputado local, seguidas muy por debajo -, Ayuntamiento y gobernador. En el distrito XX prácticamente se observó la misma tendencia por elección y partidos (Cuadro 8).

Cuadro 8 - Resultados electorales de Gobernador, Ayto. y diputado en los distritos XIX y XX en 2004 (\%)

\begin{tabular}{|l|c|c|c|c|c|c|}
\hline \multirow{2}{*}{$\begin{array}{l}\text { Partidos } \\
\text { Políticos }\end{array}$} & \multicolumn{3}{|c|}{ Distrito XIX } & \multicolumn{3}{c|}{ Distrito XX } \\
\cline { 2 - 7 } & Gobernador & $\begin{array}{c}\text { Pdte. } \\
\text { Mpal }\end{array}$ & Diputado & Gobernador & $\begin{array}{l}\text { Pdte. } \\
\text { Mpal }\end{array}$ & Diputado \\
\hline PAN & $\mathbf{5 1}$ & 50 & 44 & $\mathbf{4 3}$ & 40 & 36 \\
\hline PRI & 43 & 43 & 42 & 48 & $\mathbf{5 0}$ & 39 \\
\hline PRD & 2 & 3 & $\mathbf{6}$ & 3 & 4 & $\mathbf{4}$ \\
\hline PT & 1 & 2 & $\mathbf{4}$ & 3 & 3 & $\mathbf{1 6}$ \\
\hline PVEM/C & 1 & $0.6^{*}$ & $\mathbf{2}$ & 2 & $0.4^{*}$ & 2 \\
\hline Nulos & 2 & 1.4 & 2 & 1 & 2.6 & 3 \\
\hline TOTAL & 100 & 100 & 100 & 100 & 100 & 100 \\
\hline
\end{tabular}

* Votación de Convergencia, ya que PVEM y PBS compitieron en la Alianza Mazatlán Nos Une con el PRI.

Fonte: Elaboración propia con datos obtenidos del Estudio Panel sobre comportamiento electoral en Mazatlán, Sinaloa, 2004.

Con ello, es posible creer entonces que los electores que pensaban votar por el PRD y PT mudaron su preferencia hacia algunos candidatos con 
mayores posibilidades de triunfo, siendo éstos los candidatos del PAN y PRI para gobernador y presidente municipal. De acuerdo a este resultado se podría considerar que existen circunstancias y características distintas en cada elección. Con ello el proceso de decisión sobre la elección para gobernador, presidente municipal y diputado es distinto. Pero de los resultados y datos observados hasta el momento surgen diversas dudas: ¿por qué los electores de Mazatlán votan de esta manera? ¿Por qué en elecciones locales votan a favor de un candidato de un partido para gobernador y presidente municipal y por candidatos de otro partido para diputado local?

Al realizar un cruce de datos con la intención de voto para candidatos en las diferentes elecciones, se encontró que no existía un voto de arrastre ${ }^{4}$. En procesos electorales con elecciones concurrentes se cree que la elección principal arrastrará votos para los candidatos del mismo partido en las demás elecciones. El análisis de los datos de la tercera ronda del panel muestra que ésta es una idea por demás equivocada, por lo menos en el caso analizado. Para sustentar dicha afirmación se recurrió al cruce de datos de dos maneras: primero, con la intención de voto para gobernador y diputados locales. En segundo lugar, de manera más directa un cruce entre las variables de intención de voto para presidente municipal y diputados locales. En el primero, se observó que Félix concentró mayoritariamente la intención de voto para los candidatos de su partido. Del $39 \%$ en la intención de voto para Félix y $44 \%$ para Higuera, solamente un $24 \%$ mantenían su intención de voto por ambos candidatos, caía a $22 \%$ con Feltón en el distrito XIX y $17 \%$ con Vega en el distrito XX. Con los candidatos del PRI la cantidad de electores concurrentes fue menor. Con una intención de voto de 37\% para Aguilar en la gubernatura y $31 \%$ para Granados al Ayuntamiento, solo $20 \%$ votarían por ambos candidatos, proporción que caía a $14 \%$ con Tirado en el distrito XIX y $17 \%$ con Figueroa en el XX. La mayor cantidad de electores que dividieron su voto se encontraron entre los posibles votantes del PRI. Entre el $37 \%$ en la intención de voto para Aguilar, 11\% fueron para Higuera al Ayuntamiento, en el distrito XIX un $12 \%$ mostró la intención de votar por Felton del PAN, y en el distrito XX el $37 \%$ en la intención de Aguilar para gobernador se dividía en $17 \%$ a favor de Vega y Figueroa. Los candidatos del PRD perdían poco más de la mitad de sus electores, ya que de $11 \%$ de preferencia para Audómar a gobernador, $5 \%$ mantenía su intención de voto para Durán al Ayuntamiento, $7 \%$ para Pasos en el distrito XIX y $2 \%$ para Carrillo en el XX (Cuadro 9).

\footnotetext{
${ }^{4}$ Votación según la cual con un solo voto se consigue determinar no solo la elección de un órgano, sino de varios órganos. Así, votar por el candidato a la presidencia de la República significa simultáneamente votar por la lista de ese candidato para las cámaras legislativas y/o consejos municipales (ejemplo Uruguay). Al elector no le está permitido dividir su voto entre los diferentes órganos y partidos (Splitting) vota influido por la elección de mayor importancia, normalmente la de presidente de la República determina todas las otras decisiones.
} 
Cuadro 9 - Voto dividido en las diferentes elecciones (\%)

\begin{tabular}{|c|c|c|c|c|c|}
\hline \multirow{2}{*}{$\begin{array}{l}\text { Candidatos al Ayuntamiento } \\
\text { (3era. Ronda/octubre) }\end{array}$} & \multicolumn{4}{|c|}{ Candidatos a gobernador } & \multirow[t]{2}{*}{ Total } \\
\hline & Félix & Aguilar & Audómar & Indecisos & \\
\hline Alejandro Higuera & 24 & 11 & 3 & 6 & 44 \\
\hline MA. García Granados & 7 & 20 & 2 & 2 & 31 \\
\hline Dino Durán Ibarra & 5 & 4 & 5 & 2 & 16 \\
\hline Ns/nc & 3 & 2 & 1 & 3 & 9 \\
\hline Total & 39 & 37 & 11 & 13 & 100 \\
\hline \multicolumn{6}{|c|}{ Candidatos a diputado } \\
\hline Carlos Felton & 22 & 12 & 2 & 2 & 38 \\
\hline Irma Tirado & 6 & 14 & 2 & 2 & 24 \\
\hline Julio Pasos & 4 & 6 & 7 & 1 & 18 \\
\hline Benitez Torres & 2 & 3 & 1 & -- & 6 \\
\hline $\mathrm{Ns} / \mathrm{nc}$ & 5 & 2 & 1 & 6 & 14 \\
\hline Total & 39 & 37 & 13 & 11 & 100 \\
\hline \multicolumn{6}{|l|}{ Distrito $\mathrm{XX}$} \\
\hline Nadia Vega & 17 & 17 & -- & 6 & 40 \\
\hline Gonzalo Figueroa & 10 & 17 & -- & 7 & 32 \\
\hline Moisés Carrillo & -- & -- & 2 & -- & 2 \\
\hline Roberto Osuna & 5 & 8 & - & 3 & 17 \\
\hline $\mathrm{Ns} / \mathrm{nc}$ & 3 & -- & 1 & 4 & 8 \\
\hline Total & 35 & 42 & 3 & 20 & 100 \\
\hline
\end{tabular}

Fuente: Datos de la tercera ronda del Panel.

En lo que respecta a la intención de voto para los candidatos al Ayuntamiento y diputado local nuevamente los panistas mantuvieron mayor cohesión de electores concurrentes. En el distrito XIX un 22\% expresó su intención de voto a favor de los candidatos del PAN, la cual se incrementó al $26 \%$ para el distrito XX. Con los candidatos del PRI la proporción disminuyó nuevamente, en el distrito XIX del $31 \%$ a favor de Granados y $26 \%$ para Tirado, solo $12 \%$ manifestó votar por ambos candidatos, mientras que en el distrito XX, la intención de voto para ambos candidatos se incrementó al $24 \%$. Para el PRD en el distrito XIX un $23 \%$ que manifestaban votar por su candidato a diputado - fue la intención más alta - se distribuyó por igual $7 \%$ entre los candidatos al Ayuntamiento. Caso similar del PT en el distrito XX, donde del $18 \%$ que votaría por Osuna para diputado, $11 \%$ de ellos sufragarían por Granados al Ayuntamiento. Con estos datos es claro observar que quienes mantuvieron su preferencia sincera fueron los electores con la intención de voto para los candidatos del PAN. Por otra parte, Granados captó votos de los electores del PRD y PT que colocaron su voto como una opción con mejores posibilidades de triunfo, a pesar de que en la elección para diputado votaron a favor de los candidatos de su partido. Con esto se demuestra que al descender por el tipo de elección, se encuentra menor cohesión a favor de los candidatos de un mismo partido. En consecuencia, se observa una mayor dispersión del electorado en torno a las opciones políticas en la elección de diputado local (Cuadro 10). 
Cuadro 10 - Voto dividido en la elección de Presidente y diputados (\%)

\begin{tabular}{|c|c|c|c|c|c|}
\hline \multirow{2}{*}{$\begin{array}{c}\text { (3era. Ronda/octubre) } \\
\text { Candidatos a diputado distrito XIX }\end{array}$} & \multicolumn{4}{|c|}{ Candidatos al Ayuntamiento } & \multirow{2}{*}{ Total } \\
\hline & Higuera & Granados & Durán & Indecisos & \\
\hline Carlos Felton & 22 & 9 & 4 & 2 & 37 \\
\hline Irma Tirado & 9 & 12 & 3 & 2 & 26 \\
\hline Julio Pasos & 7 & 7 & 7 & 2 & 23 \\
\hline Benitez Torres & -- & -- & 2 & -- & 2 \\
\hline $\mathrm{Ns} / \mathrm{nc}$ & 6 & 3 & 1 & 1 & 11 \\
\hline Total & 45 & 31 & 17 & 7 & 100 \\
\hline \multicolumn{6}{|c|}{ Candidatos a diputado distrito $\mathbf{X X}$} \\
\hline Nadia Vega & 26 & 6 & -- & 8 & 40 \\
\hline Gonzalo Figueroa & 8 & 24 & -- & -- & 32 \\
\hline Moises Carrillo & -- & -- & 2 & -- & 2 \\
\hline Roberto Osuna & 4 & 11 & -- & 3 & 18 \\
\hline $\mathrm{Ns} / \mathrm{nc}$ & 7 & 1 & -- & & 8 \\
\hline Total & 45 & 42 & 2 & 11 & 100 \\
\hline
\end{tabular}

Fuente: Datos de la tercera ronda del Panel.

Al comparar los resultados electorales con el diferencial de votos por partido político entre las diversas elecciones se percibió un voto dividido. Los datos analizados hasta el momento con el cruce de la intención de voto por los distintos candidatos en las diferentes elecciones muestran que durante las campañas electorales se configuró este voto dividido. Se entiende como voto dividido al comportamiento mediante el cual se elige al candidato de un partido para un cargo de elección, pero después se eligen candidatos de distintos partidos para los demás cargos. El voto dividido puede caracterizarse como voto estratégico cuando el elector prefiere a cierto candidato (por ejemplo) a gobernador, pero no desea que este tenga una mayoría en el Congreso Local por lo cual vota por partidos contrarios en la elección de diputados. Sin embargo dos elementos impiden definir a este tipo de comportamiento como estratégico. El primero, el elector difícilmente controla en medida significativa el resultado de su voto, que resulta en cambio muy aleatorio. En segundo, raramente los partidos invitan a sus electores a comportamientos de este tipo. El voto dividido no es automáticamente asimilable al voto estratégico, aunque el voto estratégico involucra a menudo voto dividido. Pero entonces, ¿qué influencia o factores motivaron el voto dividido en Mazatlán? Las tendencias electorales analizadas en el presente trabajo mostraron que en todas las elecciones quienes mantenían la intención de votar hacia la tercera opción de la competencia (PRD/PT) orientaron su voto hacia aquellos con mayores posibilidades de triunfo, con lo que se estableció el voto estratégico (MAGALONI, 1994) ${ }^{5}$.

5 El voto estratégico indica que los votantes realizan cálculos de utilidad. Estiman las probabilidades de ganar de los distintos candidatos y deciden en consecuencia. Implica votar por el candidato con mayores posibilidades de ganar al margen de su preferencia sincera. Este tipo de voto tiene lugar solamente cuando compiten más de dos partidos políticos o candidatos en los que sólo uno es elegido. 


\section{Conclusiones}

En lo que respecta a la situación económica y el desempeño de los gobiernos, únicamente con los simpatizantes se cumple el principio de apoyar al partido que gobierna cuando la situación económica (municipal y personal) es favorable y cuando dicha gestión ha sido de sumo perjuicio la simpatía se orienta hacia un partido de oposición. Los independientes no consideraron dichos elementos como importantes en su decisión electoral. El presente trabajo reveló que con el resultado electoral en las elecciones analizadas se configuró un voto racional y estratégico por parte de los electores. El voto racional se observó con los que votaron por Félix e Higuera bajo una perspectiva que maximizaba sus beneficios. Mientras que el voto estratégico se encontró con aquellos que reorientaron su voto a favor de su segunda preferencia, siendo éstos Aguilar y Granados. Sobre los electores que modificaron su voto se encontró que quienes mantenían mayores niveles de información, alto interés en la política y las campañas, revelaron que haber votado por su preferencia sincera, manifestando altos beneficios. Quienes reorientaron su voto mostraron lo contrario, pero distinguían claramente la utilidad que generaba cada opción política. En tal virtud, puede señalarse que quienes votaron por el PAN dadas sus posibilidades de triunfo, se encontraban en condiciones de certidumbre, quienes estaban a favor del PRD y PT al mantenerse en condiciones de riesgo respecto a su preferencia sincera, por su nula posibilidad de triunfo, orientaron su voto hacia una nueva opción con mayores posibilidades (PRI), variando a condiciones de incertidumbre (SHEPSLE y BONCHEK, 2005).

En la elección de diputados se observó un bajo beneficio generado por los candidatos y en consecuencia desinterés y desconocimiento de los electores. Por ello que piensa que al elector no le importa mucho votar por un candidato a expensas de saber que no tiene posibilidades de triunfo, poco gana/pierde si su opción sincera logra el triunfo o no. Pero quizá esto sea cierto solo en parte, el resultado electoral de los candidatos a diputados del PRD y PT fue más alto que de sus candidatos en las demás elecciones. Con ello se piensa que para éstos electores la elección de diputados tuvo un significado distinto e importante, esperando que sus partidos obtuvieran amplia representación en el Congreso y con ello actuaran como contrapesos. Finalmente, se demostró que en las elecciones concurrentes donde se piensa que un candidato muy bien posicionado en la elección principal generará mayores posibilidades para los candidatos del mismo partido en las demás elecciones es una idea equivocada. En ellas se dan distintos comportamientos motivados por factores que van desde la evaluación sobre los beneficios que otorgan los candidatos hasta la situación en la que se encuentran los electores. En conclusión, regresando a la hipótesis central del presente trabajo que confrontó las posiciones políticas de los electores con los beneficios esperados en la contienda, se encuentra que dichas posiciones pasan a un segundo plano y los electores se guían principalmente por el mercado electoral esperando siempre tener algún beneficio. 
Octaviano Moya Delgado es Dr. en Estudios Sociales: Procesos Políticos, por la UAM-I, miembro del Sistema Nacional de Investigadores (Conacyt), Profesor adscrito a la Unidad Académica de Derecho y Ciencia Política, Los Mochis, UAS.

E-mail: octavianomoya@gmail.com

\section{Referencias}

BERELSON, Bernard R.; LASZARSFELD, F. Paul; MCPHEE, William. Voting. A Study of Opinion Formation in a Presidential Campaign. Chicago: University Press, 1954.

DOWNS, Anthony. An Economic Theory of Democracy. New York: Harper and Row, 1957.

EL DEBATE de Los Mochis. Tendencias electorales. El Debate de los Mochis, sección local, 23 ago. 2004, p. 22.

FIORINA, Morris. Retrospective voting in American National Elections. New Haven: Yale University Press, 1981.

MAGALONI, Beatriz. Elección racional y voto estratégico: algunas aplicaciones para el caso mexicano. Política y gobierno, México D. F., v. 1, n. 2, p. 309344, $2^{\circ}$ sem. 1994.

MORENO, Alejandro. El votante mexicano: Democracia, actitudes políticas y conducta electoral. México, D.F.: FCE, 2003.

MORENO, Alejandro; ZECHMEISTER, Elizabeth. Hacia una definición de la izquierda y la derecha en México. Este País, México D. F., n. 141, p. 1-7, dic. 2003.

MOYA, Octaviano. Comportamiento electoral e institucionalidad partidaria. Un estudio del PAN y PRD en Ahome y Guasave, de 1995 a 2001. 2003. 228 f. Tesis (Maestría en Estudios Sociales: procesos políticos), Universidad Autónoma Metropolitana-Iztapalapa, México, [2003].

NOROESTE de Culiacán. Varias ediciones. Disponible em: <www.noroeste.com.mx> Acceso en: 20 dic. 2011.

SHEPSLE, Kenneth A.; BONCHEK, Mark S. Las formulas de la politica: instituciones, racionalidad y comportamiento. México: Taurus- CIDE, 2005. 